\title{
PREPARATION AND CHARACTERIZATION OF ZnO/CuO SEMICONDUCTOR AND PHOTOCATALYTIC ACTIVITY ON THE DECOLORIZATION OF DIRECT RED 80 AZODYE
}

\author{
WALLACE J. C. DA SILVA', MARCELO R. DA SILVA², KEIKO TAKASHIMA ${ }^{*}$ \\ ${ }^{1}$ Laboratório de Processos de Oxidação Avançados, Departamento de Química, Universidade Estadual de Londrina, caixa postal 10011, \\ 86057-970, Londrina, Paraná, Brasil. \\ ${ }^{2}$ Colégio Técnico Industrial, Faculdade de Engenharia, Universidade Estadual Paulista, caixa postal 473, 17033-260, Bauru, \\ São Paulo, Brasil.
}

\begin{abstract}
Zinc oxide, an n-type semiconductor, has been used as photocatalyst for contaminated water purification by organic compounds. The addition of a p-type semiconductor as copper oxide could increase the catalytic efficiency through the p-n junction in order to decrease the electron-hole recombination. In this work, zinc and copper oxides containing 1.0,3.0, and $5.0 \%$ of copper were prepared by manual grinding, followed by heat treatment at $300^{\circ} \mathrm{C}$ during $5 \mathrm{~h}$. The zinc oxide and copper oxide mixture as well as their precursors were characterized by x-ray diffraction, diffuse reflectance, scanning electron microscopy, and x-ray fluorescence. The photocatalytic efficiency was verified by the direct red 80 tetraazodye decolorization using UV radiation under pseudo-first order conditions at natural $\mathrm{pH}(7.5-8.0)$ and $30^{\circ} \mathrm{C}$. The highest photocatalytic activity occurred to the semiconductor containing $1.0 \%$ copper oxide, whose decolorization rate constant was equivalent to $6.40 \times 10^{-2} \mathrm{~min}^{-1}$, that is, $17.4 \%$ larger in comparison to $\mathrm{ZnO}, 5.45 \times 10^{-2} \mathrm{~min}^{-1}$.
\end{abstract}

Key words: heterogeneous photocatalysis, zinc oxide, copper oxide, characterization, direct red 80.

\section{INTRODUCTION}

The exorbitant water consumption and the generation of large amounts of wastewater from several industrial sectors due to the society lifestyle have caused large problems to the environment during the last three decades. For example, the massive discharge of effluents from the textile industry, especially in the dyeing process, about $20 \%$ of dyes and large amounts of water are discarded into the streams and rivers ${ }^{1-4}$. Most of the dyes belong to the low cost azo class, with one or more azo $(-\mathrm{N}=\mathrm{N}-)$ groups bonded to the aromatic groups, which give large stability and then are not susceptible to the treatment by conventional techniques as precipitation, thermal processes, reverse osmosis, and biological treatment ${ }^{5}$.

An alternative treatment for these effluents are the advanced oxidation processes, based on the generation of the hydroxyl radical, $\bullet \mathrm{OH}$. This radical is an extremely strong oxidizing agent with high oxidation potential of $2.8 \mathrm{~V}$, short-lived and non-selective oxidation ${ }^{6}$. The heterogeneous photocatalysis mediated by an n-type semiconductor as zinc oxide is one of the most investigated advanced oxidation processes for purification of water contaminated by organic compounds ${ }^{7-10}$. When the semiconductor absorbs a photon with enough energy, the electron from the valence band is promoted to the conduction band, forming the electron-hole pair. Also, the electron reacts with dissolved $\mathrm{O}_{2}$ in water and forms the superoxide radical anion. The hole reacts with water, generating the hydroxyl radical that oxidizes the organic material. The electron-hole pair can still recombine and reduce the process efficiency ${ }^{11}$. On the other hand, this recombination could be avoided by means of the n- and p-type semiconductors coupling as $\mathrm{ZnO}$ and $\mathrm{CuO}$ respectively, generating a depletion zone in the interface, becoming more difficulty the charge return to the ground state ${ }^{12}$. Zinc oxide is non-stoichiometric $\left(\mathrm{Zn}_{1+\delta} \mathrm{O}\right)$ n-type semiconductor with the electrons excess that creates a donor band and favors the electron jump to the conduction band ${ }^{13}$. Conversely, the copper (II) oxide is a p-type semiconductor, due to the high mobility and large number of holes. ${ }^{14}$ When it is submitted to the irradiation, it acquires a partial positive charge, generating an acceptor band and becomes more difficult for the electron promotion to the conduction band. ${ }^{15}$ Considering that the copper (II) oxide absorbs radiation in the visible region and zinc oxide in the uv region limit, this pair has been applied to generate a semiconductor with $\mathrm{p}-\mathrm{n}$ heterojunction that absorbs in the UV and Vis regions ${ }^{16-18}$.

To prepare metal oxide composites, several techniques such as hydrothermal ${ }^{19-21}$, co-precipitation ${ }^{22-24}$, sol-gel ${ }^{25}$, solution combustion ${ }^{26,27}$, thermal decomposition ${ }^{28}$, and wet impregnation ${ }^{29}$ have been used. So, this work aims to prepare a low cost mixed oxide of zinc and copper from their pure oxides without residues generation, characterize and measure the photocatalytic activity for the decolorization and degradation of the direct red 80 tetraazodye (DR80, Figure 1) and compare them with pure zinc oxide.<smiles>CS(=O)(=O)c1ccc(N=Nc2ccc(N=Nc3c(S(=O)(=O)O)cc4cc(NC(=O)Nc5ccc6c(O)c(N=Nc7ccc(N=Nc8ccc(S(C)(=O)=O)cc8)cc7[S+]([O])([O-])[O-])c(S(=O)(=O)O)cc6c5)ccc4c3O)c(S(C)(=O)=O)c2)cc1</smiles>

Figure 1. Chemical structure of direct red 80 tetraazodye $\left(\mathrm{C}_{45} \mathrm{H}_{26} \mathrm{~N}_{10} \mathrm{Na}_{6} \mathrm{O}_{21} \mathrm{~S}_{6}, 7,7\right.$ '-diamino-carbonyl-[4-hydroxy-3[[sulfo-[4-[2-naphthalene sulfonate, 7,7-diamino-carbonyl] bis[4-hydroxy-3[2-sulfo-[4[(4-sulfophenyl)azo]phenyl)azo]2-naphthalene-sulfonate, C.I. 35780).

\section{EXPERIMENTAL}

Zinc and copper oxides mixture containing 1.0, 3.0, and $5.0 \%$ of copper was prepared from the grinding of adequate amounts of $\mathrm{ZnO}$ (Nuclear, $99 \%$, P.A.) and $\mathrm{CuO}$ (Synth, $100 \%$, P.A.) followed by thermal treatment. Both the oxides were added in a gradual and simultaneously way, and triturated in an agate mortar during $1 \mathrm{~h}$. Subsequently the mixture was put into an alumina crucible (Biolab, $50 \mathrm{~mL}$ ), and placed into a muffle furnace (Marconi MA 385) for $5 \mathrm{~h}$ at $300{ }^{\circ} \mathrm{C} .{ }^{30}$ The oxide powder presented gray color agglomerates.

$\mathrm{The} \mathrm{ZnO} / \mathrm{CuO}$ semiconductor was characterized using some techniques such as X-ray diffraction (XRD) in order to determine the crystallinity, using a Rigaku diffractometer D/MAX-2100/PC with the $\mathrm{Cu} \mathrm{K}(1.5418 \AA)$ radiation, coupled to a nickel filter, in order to eliminate the $\mathrm{Cu} \mathrm{K} \mathrm{K}_{\beta}$ radiation. The applied voltage was $40 \mathrm{kV}$ and the current was $30 \mathrm{~mA}$. The scanning range was from 10 to $80^{\circ}$ with a regular step of $0.05^{\circ} \mathrm{s}^{-1}$. The diffuse reflectance UV-Vis spectra (DR) was used to determine the band gap energy by means of a Shimadzu spectrophotometer UV-2600 with diffuse reflectance accessory. The morphology and distribution of the elements were obtained using scanning electron microscopy (SEM) images from a Philips FEI Quanta 200 electron microscope coupled to the energy dispersive spectrometer (EDS). The $\mathrm{Zn}$ and 
$\mathrm{Cu}$ oxides proportion was determined by energy dispersive X-ray fluorescence (ED-XRF) spectra from a Shimadzu spectrometer EDX- 800HS.

The photocatalysis was performed in a borosilicate glass reactor $(200 \mathrm{~mL})$ at $30.0 \pm 0.1{ }^{\circ} \mathrm{C}$ (Quimis Q214M2) inside a cubic wood chamber $(50 \times 50 \times 50$ $\mathrm{cm}$ ) internally covered with aluminum foil and a black curtain in the frontal part. The suspension, formed by $0.225 \mathrm{~g}$ semiconductor in $150 \mathrm{~mL}$ of $8.0 \times 10^{-5}$ mol L-1 DR80 at $30^{\circ} \mathrm{C}$, was kept in the dark under stirring (600 rpm Fisatom) during $60 \mathrm{~min}$. Afterward, the $\mathrm{Hg}$ vapor lamp without bulb (Osram, $125 \mathrm{~W}$, $220 \mathrm{~V}$ ) turned on. Aliquots $(1 \mathrm{~mL})$ were removed as a function of irradiation time, filtered (Millipore, $0.22 \mu \mathrm{m}$ ), and the remaining azo dye UV-Vis spectra (200-650 nm) were recorded (Hitachi U3000). The rate constant of azo dye decolorization, $k_{o b s}$, under pseudo-first order conditions was determined from the $\ln$ of DR80 absorbance $\left(\lambda_{\max }, 522 \mathrm{~nm}\right)$ as a function of irradiation time.

\section{RESULTS AND DISCUSSION}

Figure 2 shows the XRD patterns of zinc oxides (a) copper oxide (b) copper oxide after heat treatment at $300{ }^{\circ} \mathrm{C}$ (c) zinc oxide containing 1.0 (d), 3.0 (e), and $5.0 \%$ (f) copper oxide.

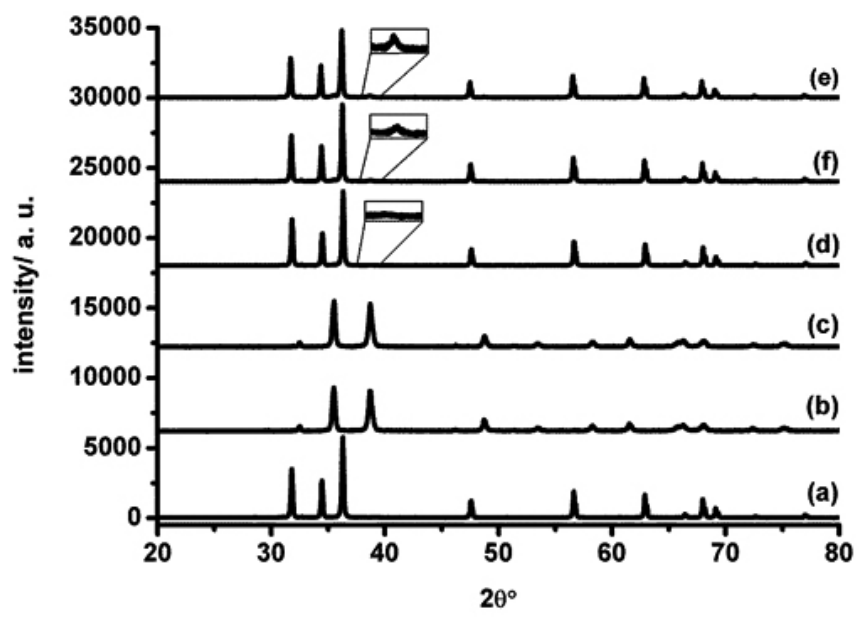

Figure 2. X-ray diffraction pattern of $\mathrm{ZnO}(\mathrm{a}), \mathrm{CuO}(\mathrm{b}), \mathrm{CuO}$ heated at 300 ${ }^{\circ} \mathrm{C}$ for $5 \mathrm{~h}$ (c), $\mathrm{ZnOCuO} 1.0 \%$ (d), $\mathrm{ZnOCuO} 3.0 \%$ (e), and $\mathrm{ZnOCuO} 5.0 \%$ (f).

Zinc oxide (Figure 2a) shows the $2 \theta$ peaks at $31.7,34.4,36.2,47.6,56.6$, $62.9,66.5,68.0,69.1,72.6$ and $77.0^{\circ}$ were identified and characterized as wurtzite phase, according to the file (PDF 13-7585) from PCPDFWIN software, version 2.4, JCODS-ICDD. The diffracted $2 \theta$ peaks at about 32.5 , $35.4,38.8,46.2,48.5,53.4,58.3,61.6,66.3,68.0,72.4$, and $75.1^{\circ}$ of copper oxide are shown respectively in Figures $2 b$ and $2 c$, are associated with the monoclinic crystal structure of copper oxide according to the file PDF 519025. The narrower peaks (Figure 2c) indicate a higher crystallinity due to the heating at $300{ }^{\circ} \mathrm{C}$ for $5 \mathrm{~h}$. The semiconductors containing 1.0, 3.0, and $5.0 \%$ copper (Figures $2 \mathrm{~d}-2 \mathrm{f}$ ) presented the same $\mathrm{ZnO}$ peaks besides a peak at $38.8^{\circ}$ indicating the $\mathrm{CuO}$ presence (Figures $2 \mathrm{e}-2 \mathrm{f}$ inserts), whose peak intensity depends on the copper oxide proportion.

The band gap energy $\left(E_{g}\right)$ of the semiconductor was determined by the diffuse reflectance spectrum, varying the wavelength from 200 to $800 \mathrm{~nm}$ as a function of the diffuse reflectance proportion. Both the $\mathrm{ZnO}$ and the oxides mixtures presented a similar reflectance profile, that is, approximately zero values from 200 to $370 \mathrm{~nm}$, enhanced to approximately $80 \%$ reflectance at $400 \mathrm{~nm}$, and remained constant at higher wavelengths. The band gap energy was calculated from Tauc model, through the conversion of the wavelength at electron volts and subsequently using $(\alpha h v)^{2}$, where $h v$ is the photon energy and $\alpha$ the absorption coefficient calculated from the reflectance, $\mathrm{R}$, shown in equation $1^{31}$.

$$
\alpha=\frac{(1-R)^{2}}{(2 R)^{1 / 2}}
$$

Thus, the band gap energy was obtained graphically from $(\alpha h v)^{2} v s \mathrm{~h} v$, extrapolating the linear part on the abscissa according to equation 2 (Figure 3).

$$
(\alpha h v)^{2}=C\left(h v-E_{g}\right)
$$

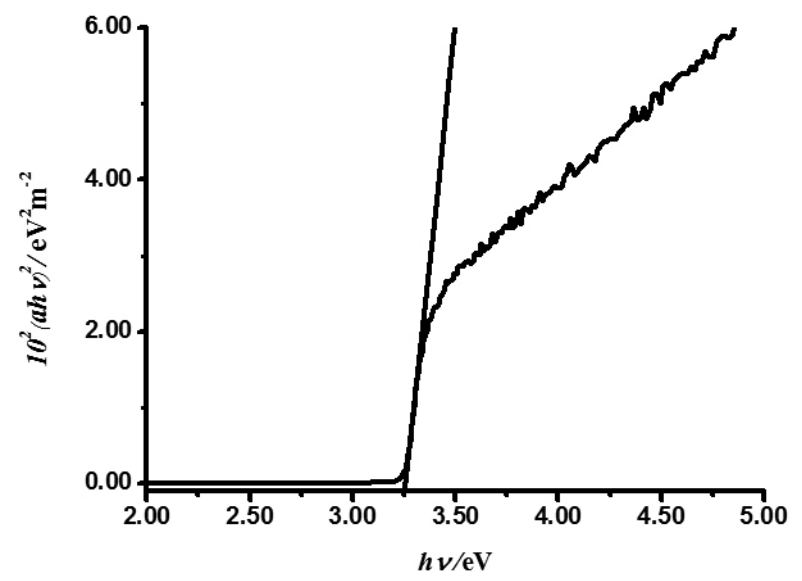

Figure 3. Band gap energy determination of zinc oxide through of Tauc model applied to the diffuse reflectance electronic spectrum.

The band gap energy was calculated as being $3.26 \mathrm{eV}$ to the $\mathrm{ZnO}$ and three prepared semiconductors. The same value of the band gap energy suggests that the $\mathrm{CuO}$ addition at different proportions was not significant to change this property. The band gap energy of pure $\mathrm{CuO}$, determined in this work, was 1.38 $\mathrm{eV}$, while it is given as $1.2 \mathrm{eV}$ in the literature. This difference can be attributed to the black color materials, as $\mathrm{CuO}$, which absorb all the wavelengths and then, making the visualization of the reflectance jump difficult.

The precursor's purity and the percentages of each component of the mixture of zinc oxide and copper oxide were investigated by ED-XRF and presented in Table 1.

Table 1. $\mathrm{ZnO}$ and $\mathrm{CuO}$ proportion obtained from energy dispersive $\mathrm{x}$-ray fluorescence.

\begin{tabular}{|c|c|c|c|}
\hline \multicolumn{2}{|c|}{ Theoretical } & \multicolumn{2}{c|}{ Experimental } \\
\hline $\mathrm{ZnO} / \%$ & $\mathrm{CuO} / \%$ & $\mathrm{ZnO} / \%$ & $\mathrm{CuO} / \%$ \\
\hline $99.0^{*}$ & 0.0 & 100.0 & 0.0 \\
\hline 99.0 & 1.0 & 99.0 & 0.9 \\
\hline 97.0 & 3.0 & 97.6 & 2.3 \\
\hline 95.0 & 5.0 & 96.0 & 3.8 \\
\hline 0.0 & $100.0^{*}$ & 0.0 & 100.0 \\
\hline
\end{tabular}

* Minimum purity declared by manufacturer

From this table it was found that both the $\mathrm{ZnO}$ and $\mathrm{CuO}$ showed 100.0 $\%$ purity. On the other hand, the $\mathrm{CuO}$ percentages were $0.9,2.3$ and $3.8 \%$ respectively for the mixtures containing theoretically $1.0,3.0$, and $5.0 \%$. These deviations were attributed to the preparation method from the oxides grinding, causing in the sample a non-homogeneous precursor's distribution. Also, it is relevant to point out that this analysis was performed from a single sample, remaining from other analyses carried out in this work. So, these results may have been consequent from a region containing minor $\mathrm{CuO}$ amount.

Figure $4 \mathrm{a}$ and $4 \mathrm{~b}$ show the energy dispersive spectroscopy of the $\mathrm{ZnO}$ containing $3.0 \% \mathrm{CuO}$ with $12000 \times$ magnitude. Figure $4 \mathrm{a}$ displays the copper distribution with irregular oval contour of $\sim 15 \mathrm{~mm}$ width and $\sim 10 \mathrm{~mm}$ height. On the other hand, Figure $4 \mathrm{~b}$ shows that the zinc occupied a large proportion of the investigated region. Figure $4 \mathrm{c}$ presents the image of this region obtained from the scanning electron microscopy with $12000 \times$ magnitude. Knowing that the oxygen covers the same area (not shown) occupied by zinc and copper, it may be concluded that $\mathrm{ZnO}$ particles cover the $\mathrm{CuO}$ surface, forming an interface between them. 


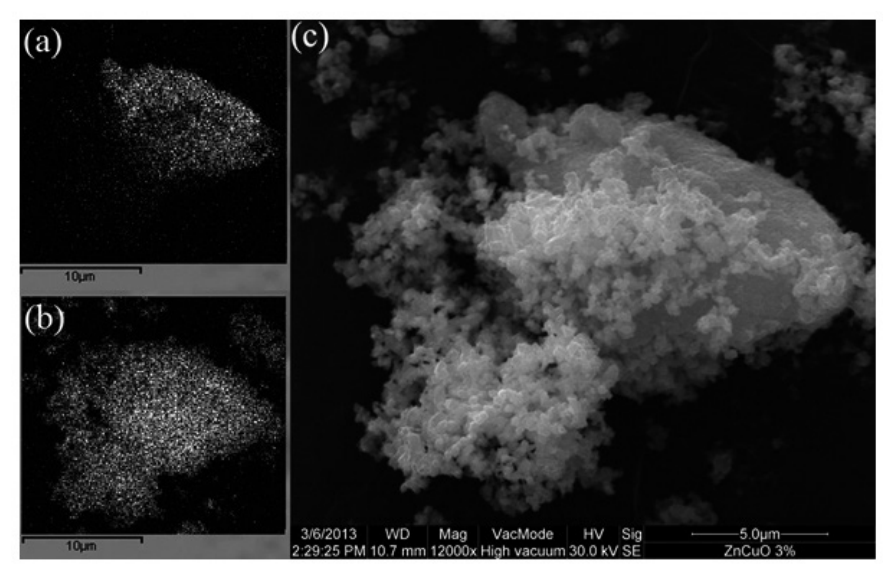

Figure 4. Electron dispersive spectrometry of copper (a) and zinc (b) distribution, and scanning electron microscopy of the semiconductor containing $3.0 \% \mathrm{CuO}$ in the same region (c).

The photocatalytic activity was investigated, measuring the decolorization rate constant $\left(k_{o b s}\right)$ of a suspension containing $1.5 \mathrm{~g} \mathrm{~L}^{-1}$ semiconductor and $8.0 \times 10^{-5} \mathrm{~mol} \mathrm{~L}^{-1}$ direct red 80 tetraazodye as a function of $\mathrm{UV}$ irradiation time at $30.0 \pm 0.1^{\circ} \mathrm{C}$. The DR80 solution presented an initial absorbance of $\sim 2.0$ that stabilized at $\sim 1.7$ at $522 \mathrm{~nm}$, after the dye adsorption, on the semiconductor surface in the dark for $60 \mathrm{~min}$. The direct red 80 decolorization rate constant at natural $\mathrm{pH}(7.5$ to 8.0$)$ are presented in Table 2.

Table 2. Decolorization rate constant $\left(k_{\text {obs }}\right)$ of DR80 $\left(8.0 \times 10^{-5} \mathrm{~mol} \mathrm{~L}^{-1}\right)$ mediated by semiconductor $\left(1.5 \mathrm{~g} \mathrm{~L}^{-1}\right)$ at natural $\mathrm{pH}(7.5-8.0)$ at $30.0 \pm 0.1^{\circ} \mathrm{C}$.

\begin{tabular}{|c|c|c|c|c|}
\hline & $\mathrm{ZnO}$ & $\begin{array}{c}\mathrm{ZnO} / \mathrm{CuO} \\
99: 1\end{array}$ & $\begin{array}{c}\mathrm{ZnO} / \mathrm{CuO} \\
97: 3\end{array}$ & $\begin{array}{c}\mathrm{ZnO} / \mathrm{CuO} \\
95: 5\end{array}$ \\
\hline$k_{\text {obs }} / 10^{-2} \mathrm{~min}^{-1}$ & 5.45 & 6.40 & 4.73 & 3.65 \\
\hline Decolorization $/ \%$ & 96.2 & 97.9 & 94.0 & 88.6 \\
\hline
\end{tabular}

From this table, $k_{\text {obs }}$ was equivalent to $5.45 \times 10^{-2} \mathrm{~min}^{-1}$ for $\mathrm{ZnO}$ that resulted in $96.17 \%$ decolorization percentage. Meanwhile, the decolorization rate constants for $\mathrm{ZnO}$ containing $1.0,3.0$, and $5.0 \%$ of $\mathrm{CuO}$ were respectively $6.40 \times 10^{-2}, 4.73 \times 10^{-2}$, and $3.65 \times 10^{-2} \mathrm{~min}^{-1}$, corresponding respectively to $97.9,94.0$ and $88.6 \%$ of decolorization. The increase of $17.4 \%$ in $k_{\text {obs }}$ when used $1.0 \% \mathrm{CuO}$, it was attributed to the depletion region formation at the between $\mathrm{ZnO}$ and $\mathrm{CuO}$ interface, taking into account that, the band gap energy $(3.26 \mathrm{eV})$ was the same for all the oxides. Moreover, in the presence of 3.0 and $5.0 \% \mathrm{CuO}$ there were a $k_{\text {obs }}$ decrease respectively of 43.1 and $13.3 \%$ in comparison to $\mathrm{ZnO}$. In this case, the $\mathrm{CuO}$ addition to the $\mathrm{ZnO}$ may change the charge distribution on the semiconductor surface, repelling the negatively charged azodye that becomes more difficult the adsorption on the surface. Therefore, the decrease of $k_{\text {obs }}$ for 3.0 and $5.0 \% \mathrm{CuO}$ can be attributed to the repulsion effect of the azodye to be higher than the charge separation caused by the depletion zone. Saravanan et al. ${ }^{29}$ investigated the degradation of organic dyes using $\mathrm{ZnO} / \mathrm{CuO}$ proportions from 99:1 to 50:50 and they found the best photocatalytic activities took place for semiconductors containing $\mathrm{CuO}$ from 1.0 to $5.0 \%$. Liu et al. ${ }^{25}$ varied the $\mathrm{CuO}$ proportion from 0.2 to $1.8 \%$ and found a $90 \%$ degradation of acid black, when they used $1.0 \% \mathrm{CuO}$. On the other hand, Chang et al. ${ }^{20}$ obtained the largest degradation for $20 \% \mathrm{CuO}$, when they varied from 5 to $20 \% \mathrm{CuO}$.

\section{CONCLUSIONS}

The largest photocatalytic activity, measured by the $k_{\text {obs }}$ of the direct red 80 tetraazodye $\left(6.40 \times 10^{-2} \mathrm{~min}^{-1}\right)$ at $30^{\circ} \mathrm{C}$ occurred to the $\mathrm{ZnO} / \mathrm{CuO}$ semiconductor containing $1.0 \%$ copper oxide, prepared thermally at $300{ }^{\circ} \mathrm{C}$ for $5 \mathrm{~h}$ in a simple way, resulting in a $97.9 \%$ azodye decolorization in $60 \mathrm{~min}$. This photocatalytic activity was $17.4 \%$ larger in comparison to commercial zinc oxide $\left(5.45 \times 10^{-2}\right.$ $\left.\min ^{-1}\right)$, attributed to the $\mathrm{p}-\mathrm{n}$ interface formation.

\section{ACKNOWLEDGMENTS}

The authors thank to Fundação Araucária (22850/2011) for financial aid and W.J.C.S. is grateful for the scholarship.

\section{REFERENCES}

1. C. Bauer, P. Jacques, A. Kalt, J. Photochem. Photobiol. B 140, 87, (2000)

2. E. Niehues, I. S. Scarmínio, K. Takashima, J. Chil. Chem. Soc. 55, 320, (2010)

3. N. Modirshahla, A. Hassani, M. A. Behnajady, R. Rahbarfam, Desalination 271, 187, (2011)

4. F. Copaciu, O. Opriş, V. Coman, D. Ristoiu, Ü. Niinemets, L. Copolovici, Water Air Soil Pollut. B 224, 1478, (2013)

5. T. Robinson, G. McMullan, R. Marchant, P. Nigam, Bioresour. Technol. 77, 247, (2001)

6. O. Legrini, E. Oliveros, A. M. Braun, Chem. Rev. 93, 671, (1993)

7. M. A. Behnajady, N. Modirshhla, R. Hamzavi, J. Hazard. Mater. B 133, 226, (2006)

8. C. Chen, J. Liu, P. Liu, B. Yu, Adv. Chem. Eng. Sci. 1, 9, (2011)

9. E. Topkaya, M. Konyar, H. C. Yatma, K. Ozturk, J. Colloid Interface Sci. 430, 6, (2014)

10. J. Miao, Z. Jia, H-B. Lu, D. Habibi, L-C Zhang, J. Taiwan Inst. Chem. Eng. 45, 1636, (2014).

11. M. R. Hoffmann, S. T. Martin, W. Choi, D. W. Bahnemann, Chem. Rev. 95, 69, (1995)

12. W. W. Gärtner, Phys. Rev. 116, 84, (1959)

13. F. P. Koffyberg, F. A. Benko, J. Appl. Phys. 53, 1173, (1982)

14. Y. Shen, M. Guo, X. Xiaa, G. Shao, Acta Materia. 85, 122, (2015)

15. P. Malvino: Eletrônica, McGraw-Hill, São Paulo, Brazil, 1986

16. K. Fujimoto, T. Oku, T. Akiyama, A. Suzuki, J. Phys. Conf. Ser. 433, 1, (2013)

17. J.-D Kwona, S.-H. Kwonb, T.-H Jungc, K.-S. Nama, K.-B. Chung, D.-H Kima, J.-S. Park, Appl. Surf. Sci. 285, 373, (2013)

18. C. Liua, C. Caob, X. Luoa, S. Luo, J. Hazard. Mater. 285, 319, (2015)

19. C. Zhang, L. Yin, L. Zhang, Y. Qi, N. Lun, Mater. Lett. 67, 303, (2012)

20. T. Chang, Z. Li, G. Yun, Y. Jia, H. Yang, Nano-Micro Lett. 5, 163, (2013)

21. Y. Zhang, J. Yin, L. Li, L. Zhang, L. Bie, Sens. Actuators, B 202, 500, (2014)

22. Z. Liu, J. Deng, J. Deng, F. Li, Mater. Sci. Eng. 150, 99, (2008)

23. B. Li, Y. Wang, Superlattices Microstruct. 47, 615, (2010)

24. Y. Liu, J. Shi, Q. Peng, Y. Li, Chem. Eur. J. 19, 4319, (2013)

25. D. M. Fernandes, R. Silva, A. A. W. Hechenleitner, E. Radovanovic, M. A. C. Melo, E. A. G. Pineda, Mater. Chem. Phys. 115, 110, (2009)

26. S. Ekambaram, Y. Iikubo, A. Kudo, J. Alloys Compd. 433, 237, (2007)

27. T. Witoon, T. Permsirivanich, M. Chareonpanich, Ceram. Int. 39, 3371, (2013)

28. R. Saravanan, S. Karthikeyan, V. K. Gupta, G. Sekaran, V. Narayanan, A. Stephen, Mater. Sci. Eng. C 33, 4725, (2013)

29. P. Sathishkumar, R. Sweena, J. Wu, S. Anandan, Chem. Eng. J. 171, 136, (2011)

30. D. Jung, Solid State Sci. 12, 466, (2010)

31. U. Choppali, B. P. Gorman, J. Lumin. 128, 1641, (2008) 